\title{
Re-significações do humano no contexto da 'ciborguização': um olhar sobre as relações humano-máquina na terapia intensiva*
}

\author{
RE-SIGNIFICATION OF THE HUMAN IN THE CONTEXT OF THE "CIBORGZATION": A LOOKAT \\ THE HUMAN BEING-MACHINE RELATIONSHIP IN INTENSIVE CARE
}

RE-SIGNIFICACIONES DE LO HUMANO EN EL CONTEXTO DE LA ‘CIBORGUIZACIÓN’: UNA MIRADA SOBRE LAS RELACIONES HUMANO-MÁQUINA EN TERAPIA INTENSIVA

\author{
Mara Ambrosina de O. Vargas ${ }^{1}$, Dagmar Estermann Meyer ${ }^{2}$
}

\begin{abstract}
RESUMO
Discutem-se relações humanomáquina do processo denominado 'ciborguização da enfermeira' na terapia intensiva, com base nos Estudos Culturais pós-estruturalistas, destacando-se o conceito de ciborgue de Haraway. Examinamse, como textos culturais, manuais utilizados pela enfermagem nas UTI. Esta análise cultural procura tensionar sentidos de 'humano e máquina', com o objetivo de reconhecer processos que instituem enfermeiras como ciborgues. Argumenta-se que enfermeiras intensivistas são inseridas em um processo de corporificação de tecnologia que transforma o corpo-profissional em um híbrido que permite desqualificar, concomitantemente, noções como máquina e corpo 'em si já que é a hibridização entre 'um e outro' que conta, ali. Como ciborgues, enfermeiras intensivistas aprendem a 'estar com' a máquina e essa conexão delimita a especifici-dade de suas ações. Sugere-se que processos de ciborguização como esse são produtivos para questionar - e lidar de outros modos com os sentidos de 'humano' e 'humanidade' que sustentam grande parte do saber/fazer em saúde.
\end{abstract}

\section{DESCRITORES}

Estudos culturais e educação. Sistemas homem-máquina. Unidades de terapia intensiva. Cuidados de enfermagem

\begin{abstract}
This study discusses the human being-machine relationship in the process called "cyborgzation" of the nurse who works in intensive care, based on post-structuralist Cultural Studies and highlighting Haraway's concept of cyborg. In it, manuals used by nurses in Intensive Care Units have been examined as cultural texts. This cultural analysis tries to decode the various senses of "human" and "machine", with the aim of recognizing processes that turn nurses into cyborgs. The argument is that intensive care nur-ses fall into a process of "technology embodiment" that turns the bodyprofessional into a hybrid that makes possible to disqualify, at the same time, notions such as machine and body "proper", since it is the hybridization between one and the other that counts there. Like cyborgs, intensive care nurses learn to "be with" the machine, and this connection limits the specificity of their actions. It is suggested that processes of "cyborgzation" such as this are useful for questioning - and to deal with in different ways - the senses of "human" and "humanity" that support a major part of knowledge/action in health.
\end{abstract}

\section{KEY WORDS}

Cultural studies and education. Man-machine system. Intensive care units. Nursing care.

\section{RESUMEN}

Se discuten relaciones humanomáquina del proceso denominado 'ciborguización de la enfermera' en la terapia intensiva, con base en los Estudios Culturales post-estructuralistas, destacándose el concepto de ciborgue de Haraway. Se examinan, como textos culturales, manuales utilizados por la enfermería en las UCIs. Este análisis cultural procura tensionar sentidos de 'humano y máquina', con el objetivo de reconocer procesos que instituyen enfermeras como ciborgues. Se argumenta que las enfermeras intensivistas son insertadas en un proceso de corporificación de tecnología que transforma el cuerpo-profesional en un híbrido que permite descalificar, conco-mitantemente, nociones como máquina y cuerpo 'en sí' ya que es una hibridización entre 'uno y otro' que cuenta, allí. Como ciborgues, las enfermeras intensi-vistas aprenden a 'estar con' la máquina y esa conexión delimita la especificidad de sus acciones. Se sugiere que procesos de ciborguización como ése son productivos para cuestionar - y lidiar de otros modos con los sentidos de 'humano' y 'humanidad' que sustentan gran parte del saber/hacer en salud.

\section{DESCRIPTORES}

Estudios culturales e educación. Sistemas hombre-maquina. Unidades de terapia intensiva. Atención de enfermería.
* Extraído da dissertação "Corpus ex machina: a ciborguização da enfermeira no contexto da terapia intensiva", Faculdade de Educação da Universidade Federal do Rio Grande do Sul (UFRGS), 2002.

1 Mestre em Educação. Professora Adjunta na Enfermagem/UNISINOS, Enfermeira Assistencial do Centro de Tratamento Intensivo Adulto do Hospital de Clínicas de Porto Alegre/UFRGS. maraav@terra.com.br

2 Doutora em Educação. Professora Adjunta na Faculdade de Educação da UFRGS. Atual coordenadora do grupo de Estudos de Educação e Relações de Gênero, na mesma instituíção. esterman.ez@brturbo.com 
Mara A. de O. Vargas

Dagmar Estermann Meyer

(a) Manual é usado aqu como todo material didático que subsidia a capacitação em sentido amplo das profissionais enfermeiras que atuam no contexto das UTIs. $\mathrm{E}$, nesta investigação, como procuramos abranger os manuais de equipamentos, fixamos como critério de inclusão: ter sido escrito na íntegra por enfermeiras intensivistas brasileiras ou no caso de terem sido escritos ou organizados por médicos/as intensivistas brasileiros/as, conter capítulos específicos para a enfermagem e escritos pelas enfermeiras; os manuais deveriam, na capa do mesmo ou já na introdução se autodenominarem de manuais os manuais do equipamentos, por sua vez, poderiam ter ser escritos no país de fabricação deste equipamento, desde que o mesmo estivesse traduzido para a língua portuguesa e representasse um equipamento com expressiva demanda de consumo nas grandes UTIs brasileiras. Balizadas nestes critérios, constituímos um conjunto de 9 manuais, publicados entre $1997 \mathrm{e}$ 2001, com exceção do manual Rotinas em terapia intensiva, amplamente conhecido no Brasil, que teve as suas três edições (1990, 1993 e 2001) analisadas. ${ }^{(1)}$

\section{INTRODUÇÃO}

Este artigo é parte da dissertação intitulada Corpus ex machina: a ciborguização da enfermeira no contexto da terapia intensiva ${ }^{(1)}$ em que se discutiu o que chamamos de "processo de ciborguização da enfermeira' na unidade de terapia intensiva, tomando como referência os Estudos Culturais que se aproximam do Pós-Estruturalismo de Michel Foucault. No contexto desse referencial apoiamo-nos especialmente em Haraway $^{(2-4)}$ e seu entendimento de ciborgue porque consideramos que esta noção é muito produtiva para explorar a ciborguização da cultura contemporânea e suas implicações para a enfermagem em terapia intensiva. A perspectiva adotada pela autora permite pensar o ciborgue como um híbrido humano - máquina que, como todo híbrido que resulta da fusão de entes de natureza diversa, não pode mais ser reduzido ou reconduzido a nenhuma humanidade, natureza ou tecnologia original. Essa figura do ciborgue torna ambíguas as fronteiras onde as diferenças entre máquinas e humanos são definidas e desconsidera um a priori de "naturalidade", o que nos permite sustentar a noção de que a interface do que é considerado "natural" e "nãonatural" não só está inserida, mas é mesmo produzida em práticas culturais e sociais complexas e, em última análise, contingentes.

Para desenvolver o estudo citado, escolhemos como corpus de análise, dentre vários materiais pedagógicos disponibilizados para as equipes de enfermagem em terapia intensiva, alguns dos manuais mais utilizados nesse contexto, no Brasil ${ }^{(a)}$. Procuramos examinar e discutir os posicionamentos do humano e/ou da máquina operados pelos discursos que constituem o saber/fazer assumido e legitimado nestes manuais com o objetivo de dar visibilidade à ambigüidade e à conflitualidade que permeiam esta relação no contexto da UTI. Portanto, desde a perspectiva teórica pós-estruturalista, e sob os pressupostos da análise cultural, os manuais funcionaram como textos culturais que nos permitiram discutir mudanças das/nas práticas da enfermeira intensivista mediante sua imbricação com os equipamentos da tecnobiomedicina, da bioeletrônica e da informática.

A análise cultural é "uma abordagem teóricometodológica cuja ênfase está colocada na descrição e na análise dos mecanismos pelos quais a cultura se articula com o conhecimento e o poder" para produzir significados ${ }^{(5)}$. Dessa forma, ela possibilita tanto romper com a linearidade e a homogeneidade que delimitam noções como hu- mano e máquina quanto explorar a conflitualidade imbricada nessa relação, naturalizada em nossa cultura como uma oposição binária que seria constituída por pólos unívocos e independentes. Em nossa análise trabalhamos fundamentalmente com a estratégia da desconstrução, a qual envolve problematizar e historicizar as oposições binárias que compõem o texto que está sob exame ${ }^{(6-7)}$, para tornar visíveis as operações de poder que estão implicadas com a sua produção. A problematização e o deslocamento operados por esta análise permitem tanto compreender as formas pelas quais as oposições se estruturam discursivamente, quanto os seus efeitos sobre os sujeitos e práticas que são conformadas por esses (e dentro desses) processos de significação. Desta forma, essa estratégia permite, dentre outras coisas, compreender criticamente os processos de significação em que estamos envolvidos quanto recusar verdades únicas e 'naturalmente dadas', que são sustentadas, exatamente, por regimes de saber-fazer que têm a pretensão de nos fornecem uma única possibilidade de ver e entender o mundo.

Tendo situado o contexto mais amplo do estudo pretendemos descrever e discutir, neste artigo específico, algumas das tensões e ambiguidades constitutivas da relação humanomáquina e seus desdobramentos, assumindo uma perspectiva que se afasta daquelas que posicionam a enfermagem como interface de humanização - como ela vem sendo usualmente representada - porque consideramos que esta discussão pode contribuir para a reflexão demandada por um contexto em que se fortalecem os discursos sobre a humanização do cuidado em terapia intensiva. Ao fazê-lo, com a abordagem que utilizamos nesta análise, não temos a pretensão de estar apresentando um modo de ver que seja mais completo, privilegiado ou verdadeiro do que outros que circulam em nosso âmbito profissional e nem estamos supondo que este modo de ver seja capaz de nos permitir uma aproximação da realidade da UTI tal qual ela é 'de fato', 'concretamente' ou em sua essência. Estamos, de um outro lugar e com outro olhar, exercitando a produtividade de problematizar algumas das questões que têm se colocado como centrais para o exercício da enfermagem contemporânea, em ambientes altamente tecnologizados como o são as unidades de terapia intensiva.

\section{DA RELAÇÃO HUMANO-MÁQUINA: AMBIGÜIDADES E TENSÕES}

Um dado que emergia das leituras que fazíamos dos estudos até aqui escritos sobre o uso 
da tecnobiomedicina ou das tecnologias nas UTIs é que, mesmo abordando questões éticas extremamente importantes e pertinentes acerca das possibilidades e impossibilidades de se lidar com os "avanços" da indústria tecnobiomédica, grosso modo, tais estudos estão balizados em referenciais teóricos que buscam preservar ou pretendem resgatar uma essência de humano e uma essência de máquina nesse contexto ${ }^{(8-9)}$. Ou seja, os modos pelos quais a humanização é abordada nos manuais de terapia intensiva e que têm influenciado e moldado as atitudes das enfermeiras intensivistas quanto à tecnologização e quanto às concepções de desumanização, incorporam noções 'essencialistas' do que seja o humano:

\begin{abstract}
Muito se tem falado sobre a Humanização das Unidades de Terapia Intensiva, especialmente durante esta última década. Este tema não apenas se tem apresentado de forma cada vez mais marcante na literatura mundial, como tem conseguido competir em condições mais paritárias com temas científicos tradicionais de nossa especialidade. A prova disso é que vem recebendo tratamento de destaque, como "vedete" de muitos congressos médicos, inclusive internacionais. Sinal dos tempos! É a Terapia Intensiva, que vem mudando o enfoque predominantemente tecnicista do paciente-doença, para uma abordagem mais humanista do paciente-pessoa. Talvez esta nova tendência esteja a sinalizar as sensações e impressões subjetivas dos profissionais que atuam nas UTIs de que a excelência técnica, isoladamente, embora necessária, não é suficiente para alcançar a recuperação do paciente crítico, em sua plenitude biopsicossocial ${ }^{(10)}$.
\end{abstract}

Na citação acima, podemos ver operando, além de uma concepção de humano essencializada, com valor de fim em si mesmo e com um conjunto de características específicas e singulares produzidas e sustentadas pela filosofia humanista, o arcabouço teórico do discurso médico-científico hegemônico. Portanto, um discurso médico-científico que aparece neste excerto, 'travestido' de uma preocupação humanista com o paciente-pessoa, em contraposição ao enfoque tecnicista imbricado na posição de sujeito paciente-doença. Dizemos 'travestido' porque, além da dicotomia pacientepessoa/paciente-doença funcionar como uma hierarquia no contexto desse discurso, em nenhum momento qualquer de seus pólos é problematizado com relação ao seu caráter construído, uma vez que tais dicotomias estão imbuídas das noções de essência e de verdade que lhe dão sustentação. Assim, a relação doença/paciente/pessoa sustenta, de alguma forma, termos intocáveis que não têm sido colocados sob suspeita.
No contexto de tais discursos, médicos/as, enfermeiras intensivistas e psicólogos/as têm sido colocados na posição de especialistas que chamam para si a autoridade de definir o que é humanização na UTI. São esses e essas especialistas (experts) que, autorizados pela posição de sujeito que ocupam no discurso científico, podem dizer sobre a humanização. Nesse sentido, podese dizer que essa é, literalmente, uma 'conversa carregada de poder', na medida em que, no contexto de tais relações de poder, os enunciados contitutivos desse discurso contribuem para legitimar um determinado tipo de discursividade que quase impossibilita outras possibilidades de discutir a humanização. Por isso, parte do nosso empenho neste artigo é, exatamente, esse: o de pensar outras alternativas de acercar-nos dessa discussão e é nesse sentido que nos dispusemos a explorar a potencialidade da noção do ciborgue. Em nossa perspectiva, isso não implica em "diminuir a importância do conhecimento científico-médico. Em vez disso, [implica] questionar tal conhecimento como constituidor da visão definitiva e única de questões" como essas que envolvem a relação estabelecida entre a humanização e a tecnologização ${ }^{(6)}$.

Para começar a explorar o que vimos dizendo, de forma mais situada, nos reportamos ao manual Rotinas em Terapia Intensiva. As duas primeiras edições fazem referência, sem muita amplitude, à intensificação da tecnologização nas UTIs. A edição de 1993 estabelece uma discussão ainda incipiente sobre o tema, abordando questões éticas do atendimento ao/à paciente internado/a em CTIs. Já a edição de 2001 introduz, ainda no primeiro capítulo, a questão da humanização, de forma mais detalhada, em diversos ítens. Por sua vez, cada um desses itens arrolados, estão imbricados, sempre, em uma relação em que se opõe humanização $\mathrm{X}$ tecnologização. Destacamos, aqui, o quarto e o quinto itens $-\mathrm{a}$ interface com o equipamento e o ambiente hostil:

A INTERFACE COM O EQUIPAMENTO [...] Médicos, enfermeiros, familiares e, às vezes, os próprios pacientes passam a interagir com o equipamento. O fato mais chamativo é daquele familiar que antes de falar com o médico traz a informação de que a freqüência cardíaca de hoje está diferente da de ontem e que o respirador ontem estava em CPAP e hoje está em CMV...?! Ou, como tive a oportunidade de testemunhar, uma paciente que controlava constantemente o oxímetro, dando inclusive um nome à luz vermelha que luzia em seu dedo: "Olho do Diabo". Observa-se o significado que o fato assumia para ela. Uma equipe bem-ori-
Re-significações do homem no contexto da 'ciborguização': um olhar sobre as relações humano-máquina na terapia intensiva

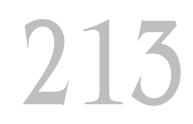

Rev Esc Enferm USP 2005; 39(2):211-9. 
Mara A. de O. Vargas

Dagmar Estermann Meyer entada deverá trazer as relações de volta para o nível humano. O equipamento é coadjuvante na assistência. Durante o período de informações aos familiares e ao paciente, o médico, o enfermeiro, o fisioterapeuta, ou outro qualquer deve chamar a si a responsabilidade de não mecanizar o atendimento e uma das formas é não dar relevância maior aos dados obtidos pelas máquinas, como parâmetros hemodinâmicos, respiratórios, mas fixando-se na situação clínica e nos seus envolvimentos existenciais. 5. O AMBIENTE HOSTIL [...] Não custa lembrar que a humanização é a palavra-chave. Uma área adequada, com dependências adequadamente desenhadas, uma equipe treinada e alertada para um atendimento humanizado permite uma série de inovações, que passam pelo conforto do paciente e de sua família, aumentam o contato destes com a equipe assistencial, não isolando nenhuma das partes do paciente e possibilitando um atendimento integrado e integral/(11).

Muitos aspectos importantes para a discussão das tensões entre humanização/tecnologização podem ser destacados nessa citação. Em primeiro lugar, os discursos que atravessam e se articulam nesse excerto parecem colocar os diferentes equipamentos conectados ao paciente (que são "controlados" e "manipulados" pela equipe médica e de enfermagem que trabalham na terapia intensiva) em uma posição hierarquicamente inferior e coadjuvante daquela que define o que é próprio da dimensão do humano. Aquilo que é próprio do humano envolve tanto a situação clíncia quanto os envolvimentos existenciais do paciente e isso seria contemplado, nas palavras do autor, na medida em que houvesse preocupação com uma área física de UTI adequada, uma equipe bem treinada e alertada para um atendimento humanizado que permitisse o conforto do paciente e de sua família, que se aumentasse o contato destes com a equipe assistencial e que se possibilitasse um atendimento integrado e integral. Assim, a polaridade humano/máquina é hierarquizada, e cada um dos pólos dessa relação é posicionado em esferas distintas, sendo a máquina, nesse caso, o pólo posicionado como o que é secundário e de menor importância no atendimento ao/à paciente na terapia intensiva. Pode-se dizer que nessa citação a máquina está, de certo modo, posicionada como o grande Outro.

O Outro - a ciência e a técnica - tem sido representado pela cultura, nesse contexto de discussão, como sendo aquele que se volta contra o que se tem de mais pleno, original, verdadeiro, homogêneo, essencial e capaz de agir com liberdade: o homem - foco central de todo 'tipo' de humanismo. Nessa direção, o que é apresentado como essência de humano toma a máquina como referência e o humano é apresentado como o oposto de máquina; ou seja, a máquina assume a posição de suplemento, complemento menos valorizado em relação ao humano. $\mathrm{O}$ dualismo humano/máquina, tal como este vem sendo abordado no contexto da episteme humanista (com seus desdobramentos a partir de, e em, outras perspectivas teóricas, além da científica), carrega a intensidade da relação 'eu' com o 'outro/ ele' sendo o eu posicionado como o humano 'invadido' por esse outro, que entra em nossos espaços e nos mira a nós humanos, seus outros. Esses outros que, deliberadamente, são feitos como outros, ao mesmo tempo em que nós fazemos deles os nossos outros. Utiliza-se, assim, no excerto citado, a metáfora "Olho do diabo" para marcar a interação com a máquina e nela o diabo aparece, literalmente, como o grande Outro: aquele que, por ser diferente de Deus, difere também daquele que foi criado a sua imagem e semelhança-o humano.

No entanto, nesse deslocamento do que tem sido historicamente delimitado como o eu em função do outro, outras tecnologias passaram, em determinado momento, a ser 'naturalmente' percebidas como fazendo parte de nosso contexto de atuar profissional e humanamente. Nesse sentido é que se pode dizer que aquilo que chamamos de exterior ao que seria 'próprio do humano' é constantemente modificado e ressignificado. $\mathrm{O}$ que antes considerávamos como algo externo passa, em algum momento e sob determinadas condições, a 'fazer parte' do que é hoje entendido como humano. Por exemplo, dentro de uma CTI, ninguém pensaria em problematizar o fato de os/as profissionais utilizarem as mais diferentes soluções anti-sépticas na técnica de lavagem das mãos, alterando, com isso, a sua flora bacteriológica 'natural', que poderia ser transmitida aos/às pacientes provocando-lhes infecções. Esse procedimento simples está assentado em uma história de 154 anos - idade dessa 'descoberta' adotada hoje como princípio básico e inquestionável nesse contexto profissional ${ }^{(12)}$. Pode-se, pois, dizer que a tecnologização é um movimento bem mais antigo e dinâmico do que 'normalmente' se diz, pois máquinas e artefatos culturais que antes eram tidos como artificiais passam a fazer parte do que entendemos, em cada época, como natureza humana, ao mesmo tempo em que outros artefatos e máquinas são problematizados e con- 
siderados artificiais. Na época de Bacon, "os meios técnicos ainda eram insuficientes, e o homem podia reinvindicar sua subjetividade e seu domínio sobre o instrumental técnico"(13). Hoje, poderse-ia dizer que o ambiente técnico, aquilo que definimos como ambiente artificial, estende-se por toda a superfície do planeta, "tornando-se o meio 'natural' em que os seres humanos vivem e são produzidos"(13).

A técnica não saiu do laboratório, mas este se dilatou: com a natureza encurralada, o tamanho do laboratório tecnocientífico passou a coincidir com o tamanho do mundo ${ }^{(13)}$.

Nesse contexto de ampliação da tecnologização é que se pode discutir a emergência de um discurso que apresenta a mecanização do atendimento na UTI como algo que funciona "em detrimento" de um atendimento integrado e integral. Tal atendimento integral (como se pode deduzir através de algumas das afirmações do autor do excerto) é apresentado como sendo capaz de preservar a integridade e a interioridade do ser humano, pois promoveria o encontro com o paciente (presença em si), resgatando o seu sentido, colocando-se a serviço de sua própria existência e conhecimento interior (subjetividade). Poderíamos, aqui, fazer-nos algumas perguntas: como e quem determina esse sentido e essa existência? Onde a integralidade se diferencia do atendimento mecanizado? $\mathrm{O}$ atendimento mecanizado seria sempre e necessáriamente definido como não-presença, conhecimento externo, artificial e objetivo? Atendimento integral não poderia ser, também no âmbito desse pensamento, traduzido como um conhecimento externo, objetivo e constituído sobre as bases do que conta como atendimento integral e integrado no contexto dessa oposição?

Sem desmerecer a relevância da experiência individual de cada pessoa - nesse caso, o/a paciente e o/a profissional (porque esta existe e precisa ser considerada) - também o termo "interface", da forma como foi utilizado no excerto ora analisado por nós, parece anunciar uma versão negativa da interação humano-máquina. Contrapõese, pois, a um sentido mais positivo do termo "interface", tal como este vem sendo definido, por exemplo, no The cyborg handbook ${ }^{(14)}$, onde interface é entendida como uma superfície que forma uma fronteira comum, um ponto de encontro ou área de contato entre objetos, sistemas, etc. Desde essa perspectiva, nesse outro manual, que opera com outro refe-rencial teórico, explorase a metáfora da 'simbiose' com o objetivo de enfatizar uma discussão acerca do desenvolvimento das interfaces para além da dicotomia hu- mano/máquina, considerando que isso é necessário para desencadear outras combinações e, com isso, outras formas de viver na contemporaneidade.

Mas os enunciados que se propagam a partir de um discurso que sustenta a polaridade humano/ máquina são mesmo múltiplos e conflitantes. Consideremos, por exemplo, o sentido e a função do olhar, desde a referência feita por uma enfermeira:

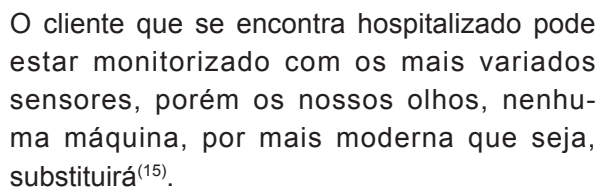

A relação 'olhar da enfermeira/olhar da máquina' é apresentada, aqui, como se o olhar da enfermeira, quando não está mediado pela máquina, fosse um olhar que antecede qualquer processo de significação; seria a 'presença em si' da enfermeira que asseguraria a qualidade do nosso atendimento. Quando o olhar da enfermeira passa a ser mediado pela máquina ou quando é a própria máquina quem olha, levanta-se o pressuposto de que esse olhar pode não ser tão confiável assim. Seria um olhar não-presente, não-próprio do que é humano. Na perspectiva da teorização cultural que adotamos, podemos, no entanto, perguntar: o nosso olhar já não é sempre mediado pela cultura? Não seria, desde sempre, um olhar construído? Ainda nessa direção de estabelecer, ou resguardar, limites entre o humano e a máquina, o capítulo 67 do manual Rotinas em Terapia Intensiva, referente à Enfermagem em Terapia Intensiva, propõe-se a discutir itens que compõem a dinâmica do trabalho de enfermagem em um CTI. E, neste processo de detalhamento do que constitui a dinâmica do serviço de enfermagem, as autoras do capítulo enfatizam:

\section{Os profissionais que lidam no seu cotidiano com processos mecanizados, mesmo quando essa tecnologia é posta a serviço da vida e da saúde de seres humanos, ficam vulneráveis à perda de limites entre o humano e o inumano(16).}

Na perspectiva que se expressa aí, o tratamento tecnologizado é abordado como uma possibilidade de tornar o tratamento, que deveria ser humanizado, não humano. Com o intuito de entender como o termo "inumano" está sendo utilizado no excerto talvez devêssemos por começar perguntando: quando se fala em realizar um cuidado humanizado, fala-se em humanização ou em humanitarismo? E, se a expressão 'mais adequada' fosse humanitarismo, isso não deslocaria o foco dessa discussão para
Re-significações do homem no contexto da 'ciborguização': um olhar sobre as relações humano-máquina na terapia intensiva 
Mara A. de O. Vargas Dagmar Estermann Meyer outro campo? Ou ainda, lidar no cotidiano de uma UTI com uma intensificação da tecnologia implica desumanidade a partir de qual referente? Desde a mesma perspectiva, a inviabilidade crescente de disponibilizar tecnologia posta a serviço da vida e da saúde, aos usuários do sistema público de saúde, também não deveria ser considerada uma forma importante de desumanização?

O mesmo Manual também apresenta as noções conhecer "com maior profundidade" o/a paciente e conhecer o/a paciente como o "caso tal" como expressões que constituem uma oposição nesse contexto:

O objetivo da escala fixa é de aumentar o vínculo e conseqüentemente a responsabilidade na humanização do cuidado de enfermagem. O profissional conhece com maior profundidade o paciente/família e suas preferências, reconhece pelo nome o paciente $e$ não pelo "caso tal" (16).

Não pretendemos negar a importância de se conhecer o/a paciente do qual se cuida e trata no contexto específico da saúde, assim como também não poderíamos nos contrapor à idéia de que o/a profissional que cuida e trata deveria abordar esse/a paciente de maneira comprometida e individualizada. O que se pretende apontar é que tanto conhecer o paciente mais profundamente quanto conhecer o paciente como o "caso tal', são expressões que podem convergir para a problematização do termo "conhecer", já que estamos sempre envolvidos em um processo instável de significação. Nesse sentido, estamos sempre re-conhecendo o ser humano doente como sendo o/a paciente (ou o/a cliente, o/a usuário, etc.), mas o fazemos balizadas por um arcabouço teórico e político que nos permite conhecê-lo/a de um determinado modo e não de outro. Não haveria, desde essa perspectiva, um sujeito transcendental que pode e deve ser conhecido profundamente, de um único modo, ou de um modo melhor.

Na mesma direção desse argumento, pode-se ainda dizer que também aquilo que se denomina e apresenta como sendo "a realidade" do ambiente clínico e do cuidado à saúde poderia e deveria ser problematizada, uma vez que:

A própria forma do cuidado de saúde e das práticas do cuidado de saúde serem organizadas representa certas visões sobre o que constitui o cuidado de saúde e sobre como [e onde] deveria ser posto em prática tal cuidado de saúde. Essas visões possibilitam também alegações quanto à autoridade e possibilitam a capacidade de descartar pontos de vista com base em tal autoridade. Quais formas particulares de pensar e de representar o cuidado de saúde proporcionam legitimidade no domínio da prática da saúde e como é conferida tal legitimidade? ${ }^{(6)}$

Questões como essas nos ajudam a localizar o debate que se trava em torno dessa relação enfermagem/tecnologia em teorizações que sustentam, também, a oposição cuidar/tratar. No contexto desse movimento para resgatar o que é próprio do humano, "curar" passa a ser apresentado como um derivado da tecnologia e é contraposto ao termo "cuidar", apresentado como sendo da ordem do humano ${ }^{(17)}$. Aqui, e ao longo desses manuais, o sentido do cuidar é associado ao humano quando o que está em pauta é humanização, mas os sentidos associados ao "curar" oscilam entre uma posição problematizada, inferior e secundária e uma posição resgatada, superior e nobre. Desta forma, poder-se-ia perguntar: em que região fora da medicina científica e da terapêutica tecnológica situa-se esse "modelo de cuidar'? Sob quais critérios se decide o que é 'cuidar" e o que é 'curar'? Quem está na posição de defini-los?

E, na direção destas indagações, não poderíamos considerar que aquilo "que caracteriza a máquina nos faz questionar aquilo que caracteriza o humano: a matéria de que somos feitos"(18)? Desde essa perspectiva e contrariamente ao que está sendo dito por alguns dos manuais que ora analisamos, é justamente a artificialidade da tecnologização que coloca em questão a noção de essência da humanização. O humano seria já tecnologia e a tecnologia seria o que constitui a possibilidade do que tem sido considerado humano. A humanização, desta maneira, seria um sistema de diferenças e, nesse sistema de diferenciação, nos deparamos, também, com posições que valorizam (sem querer fazê-lo) e, ao mesmo tempo, desqualificam a tecnologização:

Ao contrário do que se possa pensar, com exceção dos respiradores mecânicos, dos desfibriladores e, talvez, dos monitores eletrocardiográficos, a tecnologia médica é mais um meio complementar a orientar no diagnóstico e no tratamento e que, em nenhuma hipótese, substitui a ação direta do médico sobre o paciente criticamente enfermo(19).

Essa citação permite que a expressão "ação direta do médico sobre o paciente" assuma uma positividade com relação à expressão "tecnologia médica". Porém, o que mais nos interessou nes- 
sa citação é a possibilidade de esmiuçá-la, demonstrando que ela posiciona a tecnologia em três diferentes "posições" que, de uma certa maneira, traduzem a ambigüidade advinda da intensificação humano-máquina no contexto da terapia intensiva. A citação inicia ressaltando (sem querer fazêlo) a imbricação da tecnologia com o/a paciente e também com o/a profissional ao simplesmente relatar que respiradores mecânicos, desfibriladores e monitores eletrocardiógrafos são intrinsecamente essenciais para definir um ambiente como terapia intensiva. Desse ponto de vista, não existe terapia intensiva sem esses equipamentos; e ela se constitui nessa, e a partir dessa, combinação. Mas a citação continua e expressa uma alteração do status da tecnologia médica quando ela é reposicionada como algo que complementa e orienta os/as profissionais no diagnóstico e tratamento de seus/suas pacientes. Nesse movimento, a tecnologia é recolocada como algo externo ao/à paciente $\mathrm{e}$ ao/à profissional. $\mathrm{O}$ final da citação, através da expressão "em nenhuma hipótese, substitui a ação direta do médico sobre o paciente criticamente enfermo", evidencia uma desqualificação da tecnologia médica e, aqui, poder-se-ia pensar que essa tecnologia médica perde mesmo, em alguma medida, seu status secundário de complemento, uma vez que é a ação direta do médico sobre o paciente que assume o caráter de intrinsecamente essencial, ficando, de certo modo, desprovida de qualquer articulação com a tecnologia médica.

No contexto dessa realção cambiante e ambígua, ser profissional intensivista treinado/a para tratar e cuidar de pacientes graves compreende, ainda, lidar com uma ampla gama de alarmes:

No fim do capítulo é fornecida uma lista dos alarmes fisiológicos de pacientes e alarmes técnicos (INOPERANTES). Mensagens de Alarme de Paciente. Mensagens de Alarme Técnico(20).

Observamos, aqui, outra polaridade: alarme fisiológico/alarme técnico. O primeiro pólo refere-se a um sinal dado pela máquina quando algum problema é detectado no/a paciente. O segundo pólo - o alarme técnico - constitui-se na possibilidade de a máquina indicar a ocorrência de algum problema em si mesma. É interessante pensar que a polaridade alarme fisiológico/alarme técnico aborda, por um lado, um alarme que detectaria o que é natural do paciente, mas mediado pela máquina; por outro, um alarme que é próprio da máquina e intrínseco a ela, portanto, também mediado pela máquina e, assim, nunca saímos de uma relação mediada, conectada, combinada. Mas, se considerarmos que natural é o que é 'próprio de alguma coisa' pode- mos também argumentar que a máquina (um 'ente' artificial), nesse caso, está mais próxima de dizer de si do que o/a paciente. É por isso que, mesmo quando

Nós verberamos com veemência o médicotecnotrônico, não podemos deixar de reconhecer o justo valor dos engenhos tecnoeletrônicos a serviço da Medicina. Não queremos correr o risco de ser comparados àquele cidadão norteamericano que, ao ver o primeiro automóvel rodando pelas ruas de Detroit, exclamou: "Muito engenhoso, mas nunca substituirá o cavalo". São os excessos e o uso indevido dos apareIhos que devem ser verberados, nunca a tecnologia em si(21).

Outro efeito da tecnologização é o reforço de um discurso de responsabilização individual dos/ as profissionais que manejam com a máquina (o que fazer com ela), com os equipamentos. A tecno-logia em si não pode ser responsável por algum imprevisto causado ao/à paciente quando em conexão com a máquina, ao contrário, é a incapacidade ou a desumanização do humano (profissional) que explica os excessos e o uso indevido da tecnologia inserida no contexto do intensivismo. E, portanto,

\section{Como praticantes do high-tec, nós devemos estar seguros de utilizar nossas aptidões e re- cursos da maneira mais apropriada ${ }^{(22)}$.}

Os mesmo discursos que posicionam o humano como 'o responsável último' pelos acontecimentos, entretanto, apontam também para as limitações do 'humano em si'. Encaminham, pois, para a necessidade da interferência da máquina para alterar algo que o humano, por si, não consegue realizar:

$\mathrm{Na}$ realização de qualquer procedimento invasivo à beira do leito no $\mathrm{CTI}$, por mais simples que seja, a enfermagem deve ter em mente que está lidando com clientes críticos. Desta forma, a unidade do cliente deve ser preparada para tal, evitando surpresas desagradáveis. Além do habitual, deve-se manter próximo o carrinho de urgência cardiorrespiratória ou as bandejas com: medicações de urgência; suporte ventilatório; suporte circulatório, venoso profundo e periférico; suporte de marcapasso temporário artificial (MP); suporte gástrico; suporte vesical; soluções salinas e glicosadas; monitor cardíaco; cardioversor/desfibrilador; oximetria de pulso; seringas, agulhas, gazes[... $]^{(15)}$.

\section{O corpo é,}

"entre outras coisas, espaço de acolhimento de forças invisíveis e sagradas, lugar de recebimento, de transmissão, em suma, de passagem de entidades e forças não-humanas"(23).
Re-significações do homem no contexto da 'ciborguização': um olhar sobre as relações humano-máquina na terapia intensiva 
Mara A. de O. Vargas Dagmar Estermann Meyer
Quando se procura traduzir esse pressuposto para a relação enfermeira intensivista-máquina, tal como está é dimensionada no excerto acima, pode-se dizer que tal enfermeira intensivista, ao corporificar tecnologia, ostenta em seu corpo orgânico uma compatibilidade total com entes ditos não-orgânicos. Não seria mais possível separar o sujeito que é corpo do sujeito que pensa com a máquina e a tecnologia deixaria, então, de ser unicamente máquina para ser máquina-pensamento, pensamento-homem, homem-corpomáquina-pensamento. Ao mesmo tempo, esse sujeito que é máquina-pensamento-corpo não conseguiria sê-lo se não estiver colocado nessa relação. Ele é um corpo profissional que aprende a estar com a máquina. A sua conexão com a máquina é sua ação específica e, fora dessa relação, nada sobra ou sobra outra coisa.

No corpo-profissional-ciborgue ocorre, pois, uma transformação do próprio corpo, possibilitando que tecnologia e corpo atuem concomitantemente. Vista dessa forma, essa concomitância não funciona da direção de preservar o eu ou o outro, mas produz outro corpo, que somente opera e se manisfesta em conexão ou em composição, juntando em um mesmo corpo a máquina e o profissional. O que conta nessa conexão é o que liga um gesto a outro $\mathrm{e}$, ainda, um corpo à máquina. $\mathrm{A}$ máquina ou o corpo 'em si' são deslocados de seu lugar de centro e, separados, passam a ter pouca importância. É apenas a hibridação de 'um e outro' que conta. E nessa direção importaria, talvez, perguntar....

\section{O QUE É MESMO UM HUMANO AUTÊNTICO?}

Posicionando-nos em relação à pergunta-título, queremos finalizar argumentando que dis- cutir o dualismo humano/máquina a partir da noção de ciborgue torna problemática qualquer tentativa de sustentar a relação eu/outro tal como ela tem sido utilizada nos manuais aqui analisados. Na perspectiva da ciborguização o humano deixa de ser o eu, mas também não seria o outro. A máquina, por sua vez, não é o outro, mas também não assumiria qualquer privilégio. A tecnologia deveria deixar de ser descrita como condição externa à constituição humana. A condição humana, por sua vez, deveria deixar de ser descrita como essência e de assumir uma posição privilegiada para a constituição de qualquer subjetividade. O que teríamos é um ciborgue, um híbrido, nem humano, nem máquina, irredutível a qualquer condição de dualismo e de hierarquia.

Nesse sentido, a opção, a priori, pelo humano ou pela máquina poderia também ser concebida como um falso dilema, uma vez que não se trataria mais de fazer nem uma avaliação pessimista e nem uma apologia da tecnologia e do processo de ciborguização, mas de reconhecer a sua inevitabilidade. Ao fazê-lo, pode-se investir no pressuposto de que, na medida em que as enfermeiras intensivistas vivem sucessivamente nesse ambiente tecnológico, elas poderão até parecer as mesmas, mas não se sentirão ou se comportarão da mesma maneira. $\mathrm{O}$ processo de ciborguização configura-se, aí, na construção do ser enfermeira em conexão com a máquina, realizando intervenções técnicas, uma vez que máquina e humano estariam implicados nas mesmas relações. Nesse sentido, a hibridização humanomáquina poderia ser pensada e tratada como um evento que qualifica a enfermeira intensivista, $\mathrm{e}$ concebê-la assim talvez nos encaminhe na direção de formas de pensar e de fazer enfermagem em terapia intensiva que escapem de alguns dos dualismos que, contemporaneamente, limitam e aprisionam nosso ser e nosso fazer profissional.

\section{REFERÊNCIAS}

(1) Vargas MAO. Corpus ex machina: a ciborguização da enfermeira no contexto da terapia intensiva. [dissertação] Porto Alegre (RS): Faculdade de Educação da UFRGS, 2002.

(2) Haraway DJ. Simians, ciborgs and women: the reinvention of nature. London: FAB; 1991.

(3) Haraway DJ. Modest_Witness @Second_Mille nnium.FemaleMan (C) Meets_OncoMouse ${ }^{\mathrm{TM}}$ : feminism and technoscience. New York: Routledge; c1997.
(4) Haraway DJ. Manifesto ciborgue: ciência, tecnologia e feminismo-socialista no final do século XX. In: Silva TT, organizador. Antropologia do ciborgue: as vertigens do pós-humano. Belo Horizonte: Autêntica; 2000. p. 37-129.

(5) Meyer DEE. As mamas como constituíntes da maternidade: uma história do passado? In: Mercado FJ, Gastaldo D, Calderón C. Paradigmas y diseños de investigación cualitativa en salud. Una antología Ibero-americana. Guadalajara: Universidad de Guadalajara; 2002. p. 375-402. 
(6) Cheek J. Postmodern and poststructural approaches to nursing research. London: Sage; 2000.

(7) Cheek J, Rudge T. Nursing as textually mediated reality. Nurs Inq 1994; 1(1):15-22.

(8) Barbosa SFF. A transcedência do emaranhado tecnológico em cuidados intensivos. Blumenau: Nova Letra; 1999.

(9) Nunes WA. Do cuidar com tecnologia à tecnologia do cuidar. [tese] São Paulo (SP): Escola de Enfermagem da USP; 1999.

(10) Orlando JMC, organizador. UTI: muito além da técnica. São Paulo: Atheneu, 2001. Humanização: não requer grande prática ou habilidade... basicamente requer boa vontade. p. 163-6.

(11) Pinheiro CTS. O paciente e seu atendimento em terapia intensiva. In: Menna Barreto SS, Vieira SRR, Pinheiro CTS, organizadores. Rotinas em terapia intensiva. $3^{\mathrm{a}}$ ed. Porto Alegre: Artmed; c 2001. p. 25-30.

(12) Carraro TE. Tecnologia e humanização: da sua união as possibilidades de prevenção de infecções. Texto \& Contexto Enferm 2000; 9(1):42-61.

(13) Sibilia P. O homem pós-orgânico: corpo, subjetividade e tecnologias digitais. Rio de Janeiro: Relume Dumará; 2002.

(14) Gray CH. Cyborg handbook. New York: Rotledge; 1995.

(15) Yako IYO. Manual dos procedimentos invasivos realizados no CTI: atuação das enfermeiras. Rio de Janeiro: Medsi; 2000.
(16) Vieira DF, Fernandes TMS, Crossetti MGO. Enfermagem em terapia intensiva. In: Menna Barreto SS, Vieira SRR, Pinheiro CTS, organizadores. Rotinas em terapia intensiva. $3^{\mathrm{a}}$ ed. Porto Alegre: Artmed, c2001. p. 613-34.

(17) Meyer DEE. Como conciliar humanização e tecnologia na formação de enfermeiras/os? Rev Bras Enferm 2002; 5(2):189-95.

(18) Silva TT. Nós ciborgues: o corpo elétrico e a dissolução do humano. In: Silva TT, organizador. Antropologia do cyborgue: as vertigens do pós-humano. Belo Horizonte: Autêntica; 2000. p. 9-17.

(19) Menna Barreto SS. Residência médica em terapia intensiva. In: Menna Barreto SS, organizador. Rotinas em terapia intensiva. Porto Alegre: Artes Médicas; 1990. p. 329-343. (Série biomédica).

(20) Hewlett Packard. HP Virídia: guia do usuário. $3^{\mathrm{a}}$ ed. Böblingen; 1999.

(21) Orlando JMC, organizador. UTI: muito além da técnica. São Paulo: Atheneu, 2001. Ser intensivista: afinal quem é esse profissional; p. 9-12.

(22) Orlando, JMC, organizador. UTI: muito além da técnica. São Paulo: Atheneu, 2001. Tratamento fútil...e furor inútil; p. 203-6.

(23) Sant'anna DB. Corpos de passagem: ensaios sobre a subjetividade contemporânea. São Paulo: Estação Liberdade; 2001.
Re-significações do homem no contexto da 'ciborguização':

um olhar sobre as relações humano-máquina na terapia intensiva
Correspondência: Maria A. de O. Vargas Rua dos Pessegueiros, 155 - Circo Colônia Canoas CEP - 92320-360 - RS 